\title{
Los misántropos de Camus y Greene: Calígula y el Dr. Fischer
}

\author{
ML. Alí Víquez Jiménez', Universidad de Costa Rica \\ Fecha de recibido: $\quad 2$ de mayo, 2016. \\ Fecha de aceptación: 5 de setiembre, 2016.
}

\section{Resumen}

Este artículo compara los personajes de Calígula y el Dr. Fischer, que aparecen respectivamente en las obra Calígula, de Albert Camus y la novela Dr. Fischer of Geneva or the Bomb Party, de Graham Greene. Sobre la base del concepto platónico de misantropía y la relación de esta con la megalomanía, se comentan una serie de paralelismos y se establecen algunas diferencias, para llegar a conclusiones de orden filosófico.

\section{Abstract}

\section{The misanthropes of Camus and Greene: Calígula and Dr. Fischer}

This paper compares the characters of Caligula and Dr. Fischer, who correspondingly appear in the works Calígula, by Albert Camus and the novel Dr. Fischer of Geneva or the Bomb Party, by Graham Greene. Upon the basis of the Platonic concept of misanthropy and the relationship between the latter and megalomania, a series of parallelisms are commented and some differences are defined in order to arrive at philosophical conclusions.

1 El ML. Alí Víquez Jiménez es docente e investigador de la Escuela de Filología, Lingüística y Literatura de la Universidad de Costa Rica. Graduado de esa misma casa de estudios con una maestría en Literatura, ahora se desempeña como profesor Catedrático e investigador. Ha sido muy publicado y sus obras han recibido importantes galardones, entre ellos, premios nacionales y elecciones de sus relatos por parte del Ministerio de Educación Pública para incluirse dentro del currículo obligatorio de Secundaria. Contacto: aliviquezj@gmail.com.

Alí Víquez Jiménez. Los misántropos de Camus y Greene: Calígula y el Dr. Fischer. Revista Comunicación. Año 37, volumen 25, número 2, julio - diciembre, 2016. Instituto Tecnológico de Costa Rica. ISSN: 0379-3974 / e-ISSN1659-3820.
PALABRAS CLAVE:

Albert Camus, Graham Greene, Literatura europea, Literatura francesa contemporánea, literatura inglesa contemporánea, literatura comparada.

KEY WORDS:

Albert Camus, Graham Greene, European literature, Contemporary French literature, Contemporary literature in English, comparative literature. 


\section{INTRODUCCIÓN}

Aunque no cuente con buena prensa, la misantropía exhibe una tradición filosófica y literaria insigne: la lista de pensadores que han desconfiado de las virtudes inherentes al ser humano y señalan su animadversión por una especie tan viciosa como la nuestra arranca desde Heráclito, Tito Livio y Séneca, Voltaire, Swift, Schopenhauer... Estos son solo algunos nombres que cabe destacar, de una lista que aquí no intentaré continuar dado que su final no se vislumbra.

¿Estado de ánimo pernicioso o conclusión filosófica seriamente meditada? Difícil de saber, aunque los testimonios de los personajes que examinaré en este trabajo apuntan (parcialmente, al menos, como se verá) a que el misántropo es un idealista decepcionado; sus expectativas son altas, pero la experiencia lo desilusiona. Ya Platón explicaba en el Fedón la misantropía en estos mismos términos, como resultado de una generalización apresurada que ha partido de la confianza excesiva injustificada: “... la misantropía se insinúa en nosotros como consecuencia de tener sin conocimiento una excesiva confianza en alguien, y considerar a dicho individuo completamente franco, sano y digno de fe, y descubrir poco después que era malvado, desleal y, en una palabra, otro. Y cuando esto le ocurre a uno muchas veces, y especialmente ante los que se habían podido considerar como los más íntimos y más amigos, por tropezarse con frecuencia, termina uno por odiar a todos y considerar que en nadie hay nada sano en absoluto." (Platón, 1983, pp. 197-198). Unas líneas adelante, por boca de Sócrates también, hace ver que la humanidad está compuesta más por medianías que por extremos: la mayoría no se merece un odio tenaz por sus grandes vicios, pero tampoco es acreedor del amor que nace de la admiración por las grandes virtudes. Pareciera que en Platón la cura de la misantropía proviene de la aceptación resignada de la tibieza humana: no somos tan malos como para que valga la pena odiarnos, ni tan buenos como para entusiasmarnos por todo lo que hay de inmaculado en el ser humano.

La misantropía es pues un error de juicio, según Platón. Es el trato con algunas personas reales que -no sabemos si por mera mala suerte- no resultaron un buen ejemplo lo que lanza al misántropo hacia el amor de su perro, fiel animal que sabe estar a la altura, pero acaso a la altura de la sumisión que en el corazón del misántropo se exige. El misántropo solamente toleraría un mundo en el que los demás se comportasen como él lo desea; su odio por los seres humanos se origina en el hecho de que estos se salen de las normas que su ego considera indispensables. Entonces, no debemos pasar por alto que hay en la misantropía otro elemento: el puesto privilegiado que el misántropo le da a sus propios requerimientos acerca de la conducta ajena. Esto excede la postura de Platón, y convierte a la misantropía en algo más que un mero error de juicio: solo puede ser misántropo aquel que ve en sí mismo al poseedor de una verdad absoluta en cuanto a la virtud, a la cual se deberían someter los demás. El misántropo razona mal, y también se quiere superior moralmente ante los otros, cuya desobediencia lo irrita. Queda explicada la preferencia por el humilde perro de parte de este megalómano. Y esto ocurre incluso cuando el misántropo se incluye a sí mismo dentro de la especie que desprecia; Boswell escribe, atribuyendo la cita a un tercero: "I hate mankind, for I think myself one of the best of them, and I know how bad I am." (1833, p. 227). Nótese aquí que aunque el misántropo se incluye dentro de los malos, se sigue juzgando de los mejores. El menos malo, al decir de algún político costarricense tristemente célebre por este lema.

Este documento trata de comparar a dos personajes ficcionales en los que claramente prevalece la tendencia misantrópica. Uno es de Albert Camus; es el protagonista de la obra teatral homónima: Calígula. El otro es de Graham Greene y también aparece en el título de la novela: el Dr. Fischer (de Ginebra). En ellos encontramos, según veremos, a idealistas decepcionados, y también a ególatras que solamente admiten la vara de su propia autoría a la hora de medir a los demás.

La obra de Camus se estrenó en 1945; sigo la versión de la pieza que el autor dio por definitiva en la publicación de 1958. Dr. Fischer of Geneva or The Bomb Party es una novela cuya primera edición data de 
1980². Existe, pues, cierta cercanía temporal, pero aspiro a demostrar una mucho más importante: la cercanía filosófica que, hasta donde tengo noticia, se ha pasado por alto. En dos ensayos previos ${ }^{3}$ me ocupé de comparaciones frecuentadas por la crítica camusiana, con Dostoievski y con Kafka. Aquí voy sobre un terreno menos explorado.

\section{CALÍGULA}

El punto de partida es el desengaño. Cuando se inicia la obra, Calígula ha huido y todos suponen que lo hace afectado por la muerte de su hermana y amante Drusilla. Pero la realidad es otra: Calígula se siente desengañado de manera universal. La muerte de un ser querido lo lanza a conclusiones sobre la vida humana que van mucho más allá de la pena y el duelo. "Los hombres mueren y no son felices": esta es la única verdad en el reino de lo posible. Calígula decide que no se conforma con esto. Quiere lo imposible; pide la luna. Acaso no se puede sintetizar al idealismo de una manera mejor que esta, pergeñada por Camus.

Hablo del idealismo como una posición que rechaza la realidad humana no por un afán de evasión, sino porque esta realidad se juzga inaceptable. Solo sería aceptable una realidad alterna, meramente ideal. Este mundo no. La vida humana únicamente sería satisfactoria, de acuerdo con Calígula, si diera el paso hacia lo imposible. Como lo imposible es tal, Calígula decide usar su poder como emperador para hacer que en Roma se viva en la verdad. Así se instaura su imperio de terror oficial; la verdad es horrorosa y el emperador se encargará de que a nadie se le vaya a olvidar. Más tarde nos enteraremos, por boca de Scipion (Camus, 1977, p. 30), de un tiempo en el que el aún más joven Calígula aceptaba vivir en la mentira: decía que la religión, el amor, el arte servirían para ir tirando hacia adelante. Mentiras piadosas. Ahora el emperador ha cambiado de opinión.

La verdad es que la vida carece de sentido. El nihilismo es básico para entender a Calígula, pero también

2 Desafortunada adición esta de Greene en el título: "The Bomb Party" le resta protagonismo a un personaje mucho más poderoso que el desenlace de la última fiesta que da en su casa.

3 "Clamence y el Gran inquisidor: dos jueces equivocados" y "Camus y Kafka: cuando no hay castillo", ambos en prensa en la Revista Káñina de la Universidad de Costa Rica. el hecho de que es el emperador de Roma, y como tal posee el poder para imponer a los demás su desengaño. Hay otro personaje, Hélicon, que vive bajo la misma desilusión del emperador, pero, como carece de poder alguno (es un sirviente, de padres esclavos), no hace nada. Hélicon es un nihilista que se ocupa de nada; Calígula es un nihilista que se ocupa de todo.

Existe la posibilidad de pensar que lo que diferencia a Hélicon de Calígula es su acceso desigual al poder. El poder determinará cuáles son las consecuencias de la misantropía. Calígula odia la condición humana, y extiende su odio a las personas que desean mentirse al respecto. Hay que vivir la verdad de una condición que nos condena sin excepción a la infelicidad y a la muerte. Hélicon, por su parte, piensa lo mismo sobre la vida y la mentira humanas, pero no tiene ningún medio para imponerse a los demás. Ahora bien, lo cierto es que tampoco lo desea: su nihilismo es mayor que el del emperador, porque actuar le resulta indiferente: si los otros se quieren engañar, ese no es su problema. Quizás es más congruente la posición de Hélicon, sobre todo si tomamos en cuenta el objetivo expreso de Calígula: permanecer lógico. ¿Acaso no es más lógico para un nihilista el ocuparse de nada que lo contrario? Su interacción inicial con Calígula es casi humorística, como si desdeñara el interés del emperador en la vida de los demás: "Caligula: Les hommes meurent et ils ne sont pas heureux. / Hélicon: Allons, Caïus, c'est une vérité dont on s'arrange très bien. Ce n'est pas cela qui les empêche de déjeuner." (Camus, 1977, pp. 26-27).

Calígula pone todas las cartas sobre la mesa desde el principio. "Permanecer lógico" es lo que hará, siguiendo lo que su lógica (distinta de la de Hélicon) le dicta qué hay que hacer como consecuencia del sinsentido de la vida humana. Actuar en consecuencia de esta verdad, que habrá de mostrarles a los demás. Sus objetivos, como él mismo dice, son pedagógicos: sus crímenes pretenden enseñar cuál es la realidad desnuda en la que vivimos, lo queramos o no. Se puede pensar que el poder con el que cuenta un emperador nihilista lo obliga, en su opinión, a convertirse en el maestro de su entorno. 
Una serie de personajes se opondrán a esta decisión de Calígula, pero lo que resulta más notable al respecto es que ninguno es capaz de negar su verdad. El sinsentido de la existencia humana es una certeza que comparten por igual los opositores y los seguidores del emperador. Si acaso los patricios podrían diferenciarse, pero no porque tengan una opinión contraria, sino porque carecen de opinión alguna, pues entre ellos la norma es que hay que abstenerse de filosofar. Esta última actividad solo puede traer complicaciones odiosas y le huyen como a la peste.

De hecho, todo aquel que trata de comprender a Calígula, comprende que le asiste la razón. Sobre este punto insiste Cæsonia, la fiel compañera finalmente asesinada a manos del propio Calígula, muerte a la que no ofrece resistencia porque entiende su fundamento en el absurdo vital innegable. También el joven poeta, Scipion, cuyo padre ha sido otra víctima de la crueldad del emperador, ve calmarse su sed de venganza porque descubre en sí mismo una semejanza filosófica con Calígula que es mayor que su enojo. Cuando acusa al emperador de querer asimilarse a los dioses que él (Scipion) venera, no deja de admitir que esos dioses actúan para con los seres humanos del mismo modo que lo hace Calígula, quien está muy lejos de venerarlos. Calígula, sin creer en ellos, declara que puede ejercer de dios, ya que estos vendrían a ser los responsables últimos de una existencia humana absurda, y lo que su locura de emperador hace es exactamente lo mismo: forzar a todos para que vivan en la violenta verdad de ese absurdo. Ha mejorado el trabajo de los dioses, que no siempre llevan su labor al extremo del horror sin ambages. Scipion no consigue negar que ese sadismo es la tendencia dominante de sus dioses. "La même flamme nous brûle le cœur... Je souffre aussi de ce qu'il souffre. Mon malheur est de tout comprendre." (Camus, 1977, p. 119), confiesa, al rehusarse a participar de la conspiración en contra del emperador.

Párrafo aparte se merece Cherea, un patricio también, pero que, a diferencia de los demás, sí se interesa por la filosofía. Este viene a ser la única voz disidente a la que también podemos Ilamar pensante, puesto que los otros patricios abominan de Calígula sin detenerse a considerar si hay alguna justificación para que el emperador atente contra sus privilegios: parten del hecho de que está mal que lo haga y sus razones no les importan. Son políticos conservadores y esta clase de políticos, en esta obra tanto como fuera de ella, únicamente se ocupan de defender sus propios intereses. Cherea, por su parte, se opone a Calígula con plena consciencia de cuál es la fuerza nociva a la que está combatiendo. Y bien, ni siquiera él llega a decir que Calígula se equivoca: también Cherea considera que la verdad está de parte del emperador. Sin embargo, Cherea cuestiona el que haya que vivir en la verdad; cree que es mucho más razonable vivir en la mentira y ser feliz. Roma es una gran mentira que ofrece seguridad y confort. Pasajeros y frágiles, pero es todo a lo que podemos aspirar. Calígula debe morir porque -insensato-pretende que se viva en la verdad, cuando la mentira es el único sitio que admite una existencia más o menos cómoda para unos cuantos que, como él, son los privilegiados del imperio. No considera a Calígula tanto equivocado como nocivo, y esto porque reacciona a la verdad de forma incorrecta. Le tiene muy sin cuidado (y así se lo hace ver Hélicon, cuando este lo enfrenta para decirle que apoya a Calígula) que en realidad para la mayoría de la gente en el imperio, carente de privilegios y explotada de manera inmisericorde, el gobierno de Calígula apenas sea distinto al de otros emperadores, habituados los pobres como están a sufrir bajo la bota de los gobernantes de turno. Es más, cuidado y Calígula, que carece de ambición militar para seguir expandiendo Roma tal como lo hicieron sus antecesores, no ha resultado beneficioso para la mayoría, debido a que sus crímenes de locura son mucho menos inmodestos que los crímenes "razonables" producto de las guerras expansionistas. El propio Calígula lo considera así, aunque también desdeña cualquier interés filantrópico en la plebe.

De manera que si queremos un antagonista de Calígula anclado en una verdad distinta, la decepción nos aguarda. La ausencia de un antagonista filosófico me parece uno de los rasgos más notables de esta obra. No hay, realmente, quien vea el mundo con ojos diferentes. Todos los que se ponen a pensar en ello (esto excluye pues a los patricios, que no lo hacen) rápidamente encuentran que la existencia humana carece de sentido. La justificación de este pensamiento es tan precisa que cabe en una sola 
frase: "Los hombres mueren y no son felices". Ahora bien, si le prestamos atención más en detalle, nos ponemos a pensar en si ese " $y$ " tiene alguna implicación causal, como cuando digo: "El agua está sucia y no la beberé". ¿Acaso los hombres no son felices porque se saben mortales? ¿O se trata de dos aseveraciones independientes, sin valor causal del " $y$ ", como cuando digo: "El agua está sucia y el libro está en la mesa"? Tomando en cuenta la posición del único (y ya vimos que apenas parcial) antagonista de Calígula, Cherea, este expresaría su antagonismo incompleto así: "Los hombres mueren, pero pueden ser felices por un rato si consienten en engañarse al respecto" ${ }^{\prime 4}$. Si lo explico con más detalle, desde la posición de Cherea, se trata de que Calígula tiene razón al pretender que la vida carece de sentido ya que los hombres mueren, pero se equivoca al sostener que es necesario vivir infelizmente por esta causa: bien podemos engañarnos al respecto por el tiempo que las circunstancias nos permitan.

Visto así, hay que suponer que el " $y$ " en la declaración de Calígula marca una relación causal, o de lo contrario Cherea no se opondría a él con un "pero" en vez de un " $y$ ". Los hombres son infelices porque se saben mortales: la muerte es la causa de la infelicidad humana. En realidad, parece claro que así es, cuando se recuerda que la "locura" del emperador comienza con la muerte de Drusilla y continúa con el sufrimiento que le produce a Calígula el darse cuenta de que la tristeza por esta muerte también se termina: es decir, en la vida humana nada tiene durabilidad, todo es pasajero, incluso la tristeza. También parece claro que Calígula desprecia todo aquello que nace de la voluntad de engaño presente en la postura de Cherea. Esta voluntad de engaño, en una u otra medida, abarca todo aquello que se opone al emperador. Este puede enternecerse con la poesía de Scipion, que miente que la belleza es capaz de superar a la muerte, o desdeñar más abiertamente cuando la cobardía de los patricios es el móvil por el cual estos apartan su cara de la muerte, pero en los dos casos Calígula siente desprecio porque se trata de mentiras.

Así las cosas, el único dilema posible planteado en esta obra, es entre vivir en la verdad y vivir en la

$4 \quad$ No estoy citando el texto. Elaboro lo que me parece sería una síntesis del pensamiento del personaje Cherea. mentira. El que vive en la verdad lo hace, como Calígula lo ordena, de cara al absurdo: procura saborear el vino de la muerte cuanto antes. Calígula sabe desde que comenzó su reinado de terror que tarde o temprano él mismo será asesinado, y en el fondo eso es lo que procura. El que vive en la mentira prefiere licores que lo embriaguen, de manera que consiga mirar hacia otra parte el mayor tiempo posible antes de saborear el vino de la muerte.

\section{EL DR. FISCHER}

El epígrafe de la breve novela de Greene remite, convenientemente para los propósitos de esta comparación, a César. Pertenece a Herman Melville y dice así: "Who has but once dined his friends, has tasted whatever it is to be Caesar". El Dr. Fischer es ese anfitrión que, en el transcurso de sus curiosas fiestas, consigue parecerse a César. ¿Acaso no a Julio, sino a un César posterior, Calígula?

El narrador de la novela es el personaje de Jones. Este hombre, un cincuentón de alguna cultura (redacta en varios idiomas) y pocos medios económicos, nos declara, desde la primera página, que la vastedad de su amor por la joven hija del millonario Dr. Fischer solamente se iguala a su odio por este último. La historia que va a narrar se presenta como la justificación de esos sentimientos parejos en intensidad pero disparejos en todo lo demás. Claro que siempre se puede sospechar que la intensidad los hermana de cierta manera: acaso Jones solamente pudo amar tanto a la hija del Dr. Fischer porque odió tan grandemente a este.

La explicación del amor de Jones por Anna-Luise Fischer se presenta como innecesaria: "How was it I came to love Fischer's daughter? That needs no explanation. She was young and pretty, she was warm-hearted and intelligent..." (Greene 1999, p. 11). Sí resulta mucho menos evidente por qué ella se enamoró de un hombre mayor, que ha perdido una mano y pertenece a una clase social muy inferior a la suya. La clave según Jones puede ser que Anna-Luise buscaba un padre más que un marido, precisamente por la clase de padre real que es el Dr. Fischer. 
El Dr. Fischer detesta a su hija. La razón se nos revelará más tarde: él la identifica con la madre muerta, a quien odia sobre todas las cosas porque en su opinión lo traicionó. Así que podemos rastrear el origen de la misantropía del Dr. Fischer, y llegamos al hecho de que la esposa de nuestro misántropo no se comportó a la altura de sus expectativas. Ella le fue infiel, y según parece más con el alma que con el cuerpo. Enamorada de la música de una forma que al Dr. Fischer le resultaba incomprensible, cultivó una amistad con otro melómano. El Dr. Fischer lo descubrió y se sintió humillado (más aún porque el amigo de su esposa era pobre), y se dedicó a torturar psicológicamente a su mujer hasta la muerte de esta. Así, el cuadro platónico queda planteado: una persona no se comporta de acuerdo con las expectativas del misántropo, y este recurre a generalizar que todo el mundo es merecedor del odio. Comenzando por su propia hija.

Greene quiere darle a la misantropía del Dr. Fischer una categoría divina. Es la hija del Dr. Fischer la primera en verlo así. El narrador le dice: "You make him sound like Our Father in Heaven - his will be done on earth as it is in Heaven." Y ella le responde: "That about describes him" (Greene, 1999, p. 24). Esto abre la posibilidad para leer la novela desde una perspectiva teológica muy interesante. El Dr. Fischer, al compararse con los otros ricos que aparecen en esta Ginebra llena de ventajas para las grandes fortunas, declara que su codicia es diferente. Mientras los demás viven ciegamente dedicados a acumular el dinero, el Dr. Fischer pretende algo distinto:

-You are rich man yourself. Are there limits to your greed?

-Perhaps I shall find out one day. But my greed is of a different kind to theirs.(...) I like to think that my greed is a little more like God's

-Is God greedy?

-Oh, don't think for a moment I believe in him any more than I believe in the devil, but I always found theology an amusing intellectual game. (...) Well, the believers and sentimentalists say that he is greedy for our love. I prefer to think that, judging from the world he is supposed to have made, he can only be greedy for our humiliation, and that greed how could he ever exhaust? (Greene, 1999, pp. 61-62).

Así, el Dr. Fischer representa a Dios, un dios en el cual el personaje no cree, pero al que igualmente desea emular. El Dr. Fischer se dedica a acrecentar la humillación humana. En esa dirección va su codicia. Y como los pobres ya de por sí viven en condiciones indignas, él se dedica a humillar mayormente a los ricos (claro que no pierde la oportunidad para hacerlo también con su yerno, que no tiene dinero). No es otro el propósito de sus fiestas, donde reúne a millonarios decadentes de Ginebra y les sirve alimento para caballos, con el ofrecimiento de un gran regalo si todos llegan a vaciar sus platos. La tal vez nada sorprendente comprobación del Dr. Fischer es que los ricos son una clase de gente dispuesta a lo que sea con tal de acrecentar sus fortunas, no importa si para ello deben humillarse. Y, por cierto, lo que menos les importa es que ellos ya tienen mucho dinero y carecen de una necesidad apremiante para sufrir tales vejaciones. Se entiende a un miserable que para dar de comer a sus hijos se ve obligado a someterse a lo que sea, pero resulta que los invitados a cenar del Dr. Fischer se presentan a su casa a bordo de un Rolls Royce. El asunto es este: para un rico nunca es suficiente y nunca hay algo demasiado bajo como para no hacerlo con tal de obtener más dinero. Cuando uno de los comensales no puede seguir tragando y vomita, el que está a su lado no tiene empacho en comerse los desperdicios de su colega, con tal de cumplir con las condiciones que ha puesto el Dr. Fischer para repartir los costosísimos regalos.

Por cierto que el Dr. Fischer es muy consciente de su paso desde el odio a alguien en particular hacia el desprecio por la humanidad en general. Odiar es algo que se hace particularmente; en cambio, el desprecio puede generalizarse. Para ello hace falta la decepción hacia una humanidad que no se comporta a la altura de las exigencias personales del doctor. Es como un dios desilusionado con el comportamiento esperable en las personas, que se decide entonces a experimentar hasta dónde le es posible humillar a estos débiles seres. 
El antagonista del Dr. Fischer en esta novela es su yerno, Jones. Sin ser un filósofo de profesión (tampoco parece serlo el Dr. Fischer, de quien solo sabemos que no es médico), Jones tiene algunas ideas filosóficas interesantes, que se contraponen a las de su suegro. Piensa que el sufrimiento es una condición para el crecimiento espiritual, y por ello no lo identifica con la humillación. Para el Dr. Fischer, ese dios en el que no cree le da a los seres humanos pequeñas satisfacciones para que abriguen esperanzas que luego se verán infundadas. A Jones, por ejemplo, le ha dado el amor de una joven, solo para seguirlo humillando después con una vida miserable. Pero este no lo ve así: más bien cree que el dolor es la causa de un crecimiento en la capacidad para ser feliz después. Es a esto a lo que se refiere, planteándolo primero como una broma, cuando le dice a Anna-Luise que algunas personas tienen alma y otras no: "Doesn't everybody have a soul - I mean if you believe in souls?", le pregunta ella, a lo que Jones replica: "That's the oficial doctrine, but mine is different. I think souls develop from an embryo just as we do." (Greene, 1999, p. 82). La condición para que el alma de una persona se desarrolle (eso que, más convencionalmente, he llamado "crecimiento espiritual") es que la persona sea capaz de sufrir por amor. Por ello, los egoístas no tienen alma. Jones y Anna-Luise van repasando los casos de los millonarios que rodean al Dr. Fischer y concluyen que, salvo dos personajes dudosos, ellos no tienen alma. En cambio, sí creen que el propio Dr. Fischer la tiene, pero que está dañada. No explican por qué: es posible especular que el Dr. Fischer ha sufrido por el amor a su esposa, pero como su reacción ante tal fue darles cabida al odio y al desprecio, su crecimiento espiritual resultó torcido y perverso.

Jones vive felizmente por el amor inesperado que ha llegado a su vida. Desde su punto de vista, este acontecimiento le da sentido a su existencia, incluyendo todos sus sufrimientos previos (lo que el Dr. Fischer Ilamaría "las humillaciones de Dios"). Confiaba en ser feliz ahora por el resto de su vida, pues AnnaLuise estaría a su lado. Si ella llegara a faltarle, sería porque él mismo hubiera hecho algo imperdonable, de manera que se lo tendría merecido. Siendo más de treinta años mayor, daba por descontado que él moriría primero. Pero no fue así, y aquí es donde el personaje se quiebra.

Su primer impulso es suicidarse, pero resulta torpe en la ejecución. Es entonces cuando vuelve a encontrar al Dr. Fischer, quien planea la última de sus fiestas. Las fricciones entre ellos se renuevan, ahora con una nueva variable: el Dr. Fischer llega al convencimiento de que su ex yerno no es muy inteligente si, aun después del fallecimiento de Anna-Luise, no entiende que la razón le asiste en la concepción repugnante que tiene de un dios en el cual no cree. Jones, por su parte, no le oculta cuánto lo odia por haber tratado tan mal a Anna-Luise. Cuando menciona también el desprecio, el Dr. Fischer lo corrige: "Again you are using the wrong term. Semantics are important, Jones. To despise comes out of a great disappointment. Most people are not capable of a great disappointment, and I doubt if you are. Their expectations are too low for that. When one despises, Jones, it's like a deep and incurable wound, the beginning of death." (Greene, 1999, p. 105). Así, según el Dr. Fischer, la cortedad intelectual de Jones los distingue pues solamente él, que ha tenido un horizonte mayor, es capaz ahora del desprecio por causa de la desilusión que siguió a sus grandes expectativas.

No obstante, Jones tiene una carta bajo la manga. Cuando asiste a la fiesta ("the bomb party") del Dr. Fischer, lo hace poseído por la codicia. Pero, a diferencia de los otros invitados, su codicia no es de dinero; y a diferencia del Dr. Fischer, su codicia no es de humillación. Jones solo ambiciona morir, la fiesta en la que los millonarios innobles estarán dispuestos a poner el pellejo en juego con tal de acumular más dinero (todos deben arriesgarse a que les estalle una bomba a la hora de obtener un cheque) le da la ocasión perfecta. No tiene éxito: el Dr. Fischer les ha mentido y no había tal bomba. El único que muere, por su propia mano, esa noche, es el Dr. Fischer, quien ha llegado al punto en que su desprecio por la humanidad es tal que incluso se desprecia a sí mismo. Entonces decide matarse.

Jones, antagonista hasta este momento del Dr. Fischer, sigue otro camino. En el momento en que se supone que está exponiéndose a que le estalle una bomba, piensa en que, si Dios existe, entonces el 
alma de Anna-Luise sigue viviendo y él podría reencontrarse ahora con ella, si se muere de una vez. Pero la bomba no estalla y esto produce en Jones un desencanto tal que abraza el ateísmo. El libro termina con un Jones que ya no desea suicidarse, pues ha perdido toda esperanza en Dios y en el más allá y sabe que la muerte no lo conducirá de nuevo a su amada esposa. Ese Dios que no lo mató de una buena vez no puede existir. ${ }^{5}$ Y si bien no esperaríamos en Jones una actitud de desprecio por la humanidad como la del Dr. Fischer ni un deseo de emular a un dios adicto a la humillación, sí lo vemos al final abrazar la idea, cara a su enemigo, de que la vida en este valle de sufrimientos carece de sentido.

\section{CONCLUSIONES: LOS TÉRMINOS DE LA COMPARACIÓN}

Al plantearme inicialmente esta comparación de misántropos, supuse que las posiciones filosóficas antagónicas de sus autores marcarían la pauta del trabajo. Camus, ateo y Greene, católico. Esto debía ser determinante, preví. Ahora veo que no ocurre así más que inicialmente.

Me explico. Inicialmente, se pueden contraponer el universo del Calígula camusiano y el Dr. Fischer de Greene. Puede constatarse que en Calígula no hay ningún atenuante del absurdo: convenientemente, Camus ha recurrido a recrear un mundo en el cual el cristianismo, con su confianza en el amor y la salvación, no tiene cabida ${ }^{6}$. Así, como hemos visto, no hay nada que oponer al sinsentido de la existencia que Calígula encuentra en el mundo. Este sinsentido es innegable. "Los hombres mueren y no son felices": es todo.

Por el contrario, en el mundo de Jones, la muerte y la infelicidad sí cobran sentido, dentro de una cosmovisión que, si bien no se identifica a sí misma como cristiana, sí se puede ver como inspirada en esta religión. La posibilidad de reencontrarse con Anna-

5 De nuevo se nota cómo el texto juega con el hecho de que el Dr. Fischer imita a Dios: fue el primero quien decidió no poner la bomba, pero Jones se lo atribuye al segundo. Al fin que, en buena teología, todo ocurre por voluntad de Dios.

6 Claro que no es obligatorio que el cristianismo represente la opción filosófica antagónica a la filosofía del absurdo. Pero resulta innegable que constituye una opción importante, y es al fin la que históricamente ha tenido más relevancia en occidente a la hora de construir la alternativa.
Luise es algo a lo que el personaje de Jones le da crédito, y este asocia esa posibilidad con la existencia de Dios. Los hombres, por lo tanto, no mueren, si Dios existe. En cuanto a que no sean felices, Jones lo acepta como una condición para el conocimiento posterior de la felicidad. Los hombres pueden no ser felices para después saber bien lo que es serlo.

Ahora bien, lo cierto es que Jones sale derrotado en su enfrentamiento con el Dr. Fischer, quien piensa de un modo muy distinto. Este siniestro personaje se quiere asimilarse a Dios, aunque no crea en su existencia. Pero el caso es que ese dios inexistente procura satisfacer su codicia de humillación con las vidas de los pobres seres humanos. Es un dios adicto al sufrimiento ajeno, un sádico. Jones, sin dejar por un momento de odiar al Dr. Fischer, renuncia a sus creencias cuando no consigue morir en la fiesta de la bomba. El curso de los acontecimientos lo convence no de despreciar a todo el mundo, pero sí de que la existencia humana, condenada al sufrimiento, carece de propósito. El Dr. Fischer ha ganado.

De manera que nuestros dos misántropos acaban por parecerse, en primer término, porque al final empatan a la hora de carecer de antagonista o de vencerlo. Mueren, sí, pero demuestran haber tenido la razón. Darle algún sentido a la existencia es algo imposible desde el principio para Calígula y para el Dr. Fischer, pero lo resaltable, en el segundo caso, es que también llega a ser así para el antagonista del doctor, el personaje de Jones. En cuanto a Calígula, no ha tenido jamás verdadero antagonista.

Llevados así los términos de la comparación, parece que el planteamiento de Greene es más complejo que el de Camus, pues en el universo de este último autor nada se opone realmente a la visión de mundo absurda. En cambio, en el universo de Greene, lo que ocurre es que la oposición es vencida por la fuerza de los acontecimientos. Jones tiene una propuesta válida, pero los sucesos se dan de tal modo que la abandona. Sale filosóficamente derrotado.

Por otro lado, el Dr. Fischer expone una historia personal muy semejante a la descrita por Platón. De una decepción particular pasó a una desilusión generalizada. Además, les aplica a todos la vara de sus propias expectativas, sin pararse a pensar si estas son 
justas o no. Ni siquiera le interesa si vienen al caso. El Dr. Fischer representa muy bien a ese misántropo megalómano del que comenté en la introducción, aunque con una particularidad: su idealismo en un sentido estricto no parece haber existido jamás; la conducta que esperaba de su mujer era la propia del amo que, si algo idealiza, es su dominio inapelable sobre su esclavo. Solo así se le podría llamar, con plena justificación de las comillas, "idealista".

El caso de Calígula es tanto más complejo pues el personaje no se convierte en misántropo por causa de una desilusión por la conducta de alguien en particular. Se podría argumentar lo contrario, si se piensa que se decepcionó por la conducta de Drusilla, quien muere. Pero ello no es exacto. Drusilla muere y lo que Calígula ve en este asunto concreto no es sino el secreto a voces de que todos morimos y por eso no somos felices. En realidad, Calígula no se decepciona de los demás, solamente desprecia a aquellos que no quieren vivir en la verdad. Lo que desprecia es el autoengaño, y este no lo ve primero en nadie en particular. Su misantropía está quizás menos generalizada, pues admite casos cercanos a él de personas (como Hélicon, sobre todo) que no desprecia porque no viven en la mentira de que la vida tiene sentido. Con todo, ya que la gran mayoría de quienes lo rodean desean vivir en el engaño, Calígula tiene sobradas ocasiones de despreciar a esos que solo puede calificar de cobardes. Pero se puede decir también que Calígula no odia tanto a la humanidad como a la condición humana. En su caso, su idealismo sufre una decepción filósofica, pues encuentra (muy evidentemente, ya que esto ocurre desde el principio de la obra) que no le será dado lo imposible. Quiere decirse, en su caso, la luna, esa metáfora de lo inalcanzable.

En lo que respecta a la megalomanía, mi criterio es que Calígula la padece tan severamente como el Dr. Fischer, en la medida en que ninguno de los dos es capaz de concebir que se puede equivocar. Calígula también les aplica a todos su vara personal y no le tiembla el pulso a la hora de ejecutar decisiones tan irremediables como el asesinato. En este sentido, habría que reconocerle al Dr. Fischer que al menos dejó la bomba sin conectar en su última fiesta. Ca- lígula la habría accionado fácilmente ${ }^{7}$. Ahora bien, sin duda la expresión más extrema de estas megalomanías se halla en el hecho de que los dos personajes, sin creer en los dioses, se dedican a corregir, terminar o exagerar el trabajo de estos. Ambos se ven a sí mismos en el papel de dioses, aunque no tengan fe en la existencia real de estos. Esto lo posibilita, por cierto, el poder que ambos poseen; el uno, el poder político y el otro, el económico. La misantropía exige en ambos casos un acceso privilegiado al poder para ejercerse al extremo.

Una última consideración antes de terminar. El destino común de los dos misántropos es el de terminar incluyéndose a sí mismos en su desprecio. Puestos en el camino de odiar a la humanidad (el Dr. Fischer) y a la condición humana (Calígula), no ven obstáculo en odiarse a sí mismos. Por ello, al final uno se suicida y el otro no hace nada por impedir que lo asesinen. El razonamiento con el cual ganan es el mismo por el cual pierden la vida. La misantropía se demuestra en ambos textos como una forma de imponer un pensamiento que provoca la destrucción no solo de los otros, las víctimas de su crueldad, también de quien lo posee.

\section{REFERENCIAS BIBLIOGRÁFICAS}

Boswell, J. (1833). The life of Samuel Johnson. New York: George Deaborn, Publisher.

Camus, A. (1977). Caligula, suivi de Le malentendu. Paris: Gallimard.

Cloete, N. (1998). Religious paradoxes in Graham Greene's novels. Koers, 63(2), 313-325.

Couto, M. (1979). Graham Greene: The Search for Religious Humanism. India International Centre Quarterly, 6(2), 105-113.

Genovese, M. K. (2010). Meaningful Meaninglessness: Albert Camus' Presentation of Absurdism as a Foundation for Goodness. Pell Scholars and Senior Theses. Recuperado de: http: // digitalcommons.salve.edu/pell_theses/60/, consulta el 20 de enero de 2016.

\footnotetext{
$7 \quad$ Claro que siempre es posible pensar que lo que inhibe al Dr. Fischer de accionar bombas es que él no es el emperador de Roma...
} 
Glicksberg, C. (1959). Graham Greene. Catholicism in Fiction. Criticism, 1(4), 339-353.

Glicksberg, C. y Harry T. M. (1963). The Tragic Vision in Twentieth Century Literature. U.S.A: Southern Illinois University Press.

Greene, G. (1999). Dr. Fischer of Geneva or The Bomb Party. Great Britain: Vintage.

Hochberg, H. (1965). Albert Camus and the Ethic of Absurdity. Ethics, 75(2), 87-102.

Jaskulski, G. (2009). Depriving the Symbol of Its Power: The Dissolution of Meaning in Albert Camus's Cycle of the Absurd. Senior Paper presented for a Degree Bachelor of Arts with a major in Literature. The University of North Carolina, Asheville.

Just, D. (2010). From Guilt to Shame: Albert Camus and Literature's Ethical Response to Politics MLN, 124(4), 895-912.
Onfray, M. (2012). L'ordre libertaire. La vie philosophique d'Albert Camus. Paris: Flammarion.

Peyre, H. (1958). Albert Camus, an Anti-Christian Moralist" Proceedings of the American Philosophical Society, 102(5), 477-482.

Platón. (1983). El banquete, Fedón, Fedro. Traducción de Luis Gil. Editorial Orbis, Barcelona.

Scott, N. A. (1959). The Modest Optimism of Albert Camus. The Christian Scholar, 42(4), 251-274.

Tatham, M. (1982). Alfred Jones and the Party Perilous or Misunderstanding Mr. Graham Greene. New Blackfriars, 63 (741), 131-139.

Todorov, T. (1991). Crítica de la crítica. Trad. de José Sánchez Lecuna. Barcelona: Editorial Paidós.

Vega, J. M. y Neus C. (1998). La literatura comparada: principios y métodos. Madrid: Gredos. 